\title{
SMART RAILWAY CROSSING EMBEDDED WITH AUTOMATED PLATFORM BRIDGE
}

\author{
Prashantha.B.Y ${ }^{1}$, Harisha.S ${ }^{2}$ \\ ${ }^{1}$ Asst Prof, Dept of Mechanical Engineering, Srinivas School of Engineering, Mangalore, Karnataka, India \\ ${ }^{2}$ Asst Prof, Dept of Mechanical Engineering, DY Patil School of Engineering, Ambi, Pune, Maharastra, India
}

\begin{abstract}
The objective of this paper deals with automatic railway gate opening at a level crossing without human intervention. In the present work it is proposed to substitute fully automated railway gate opening feature and as well as automated platform bridge facility in the station which helps peoples to move from flat form to flat form. Now a day all over the world accidents are common because of lack of technology, human carelessness at right time. And these accidental barriers cannot be completely avoidable but some fruitful steps definitely reduced to some extent, in account of this the initiative steps is required to avoid many humans death at any place and time by introducing new technologies, this effort has been taken in this work by adopting automatic railway gate opening without gate keeper near level crossing and automated platform bridge. The above said system works on microcontroller based technique and rack and pinion mechanism which is employed to operate Platform Bridge.
\end{abstract}

Keywords: Level crossing, Automated platform bridge

\section{INTRODUCTION}

The term "Level Crossing" dealt with the place where railway line or path crosses a road path at same level. In an India the transportation mode been highly depends on train. The reason behind this is its economical and bulky in nature, however 'Level Crossing' is the steps towards safety concern internationally. It is evident from the daily newspapers and TV channels that mishaps at level crossing is more often and its accounts $40 \%$ of train accidents this is due to use of manned gate opening and carelessness of travellers or deploying a unskilled railway gate operator, the train couldn't be stop at level crossing because it has massive mass relative to the braking distance so it is essential to clear the pedestrian and vehicles well in advance. By considering above said possibilities of collisions and fatalities, in this work effective measure should be taken by implementing microcontroller and read switch sensor based unmanned gate opening and also deploying a rack and pinion operated automated platform bridge. The read sensors senses and send a signal to the microcontroller when train come across it, And also in rest condition, then microcontroller take action in two different situations to drive the driving motor to operate opening of gate and form a platform bridge when the train leaves the station.

\subsection{Objective of Project}

The main work in this paper spread a light on three things as fallows,

- $\quad$ Provide automatic level crossing.

- Implementing automated flat form bridge.

- $\quad$ Reduce the time, which will waste during opening and closing of gate irrespective of arrival of train.

\section{LEVEL CROSSINGS ACROSS THE WORLDS}

As per the statistics provided by the railways in south western division (SWR), there are 1270 Level Crossings of which 750 are manned and 520 are unmanned. Overall, the state has 445 unmanned level crossings spread across Karnataka.

Let's take a look on the approach of Level crossings across the worlds as given bellow,

\subsection{Asia}

All Indonesia level crossings are operated automatically and use sirens in place of conventional bells.

\subsection{Hong Kong}

The underground railway network or elevated viaduct is most common in Hong Kong, this means the use of automated Level crossing are rare.

\subsection{Japan}

The japan also deployed underground railway network system across different cities, but it has established around 34000 Level crossings all around.

\section{LITERATURE SURVEY}

Acy M. Kottalil, Abhijith S, Ajmal M M, Abhilash L J, Ajith Babu [1]. The research work carried out by above mentioned authors mainly focus on preventing of skilled worker to operate railway gate near Level crossings by establishing AT mega 16A microcontroller and IR sensors based systems to control gate opening and closing by receiving the signals accordingly. 
J. Banuchandar, V.kaliraj, P.Balasubramanian, N.Thamilarsi [2]. The paper written by these authors mainly put a spot light on two things; one is the reduction of time for which the gate is being kept closed. And secondly, provide a safety to the road users to reduce the accidents by using unmanned way of opening the railway gate.

Hnin Ngwe Yee Pwint, Zaw Myo Tun, Hla Myo Tun [3]. The paper describes automatic railway gate systems by using PIC 16F877A Microcontroller for saving precious Haman lives. Here Inductive and IR sensors used as input components while buzzer, light indicator, DC motor and LCD display are the output components

Krishna, Shashi Yadav, and Nidhi [4]. The paper deals with control the railway track by using a anti-collision technique, the entire system is modeled and controlled by 8952 microcontroller to avoid the railway accidents.

\section{HARDWARE COMPONENTS REQUIRED}

The followings are used as important parts of the system to make complete skeleton of smart Railway Crossing

a) Microcontroller PIC16F877/874

b) Read switch sensor

c) Filter rectifier

d) Transformer $12 \mathrm{~V}$

f) Helical gear motor

g) Rack and pinion mechanism

\section{FUNCTIONAL VIEW OF CONTROLLING}

\section{SYSTEM}

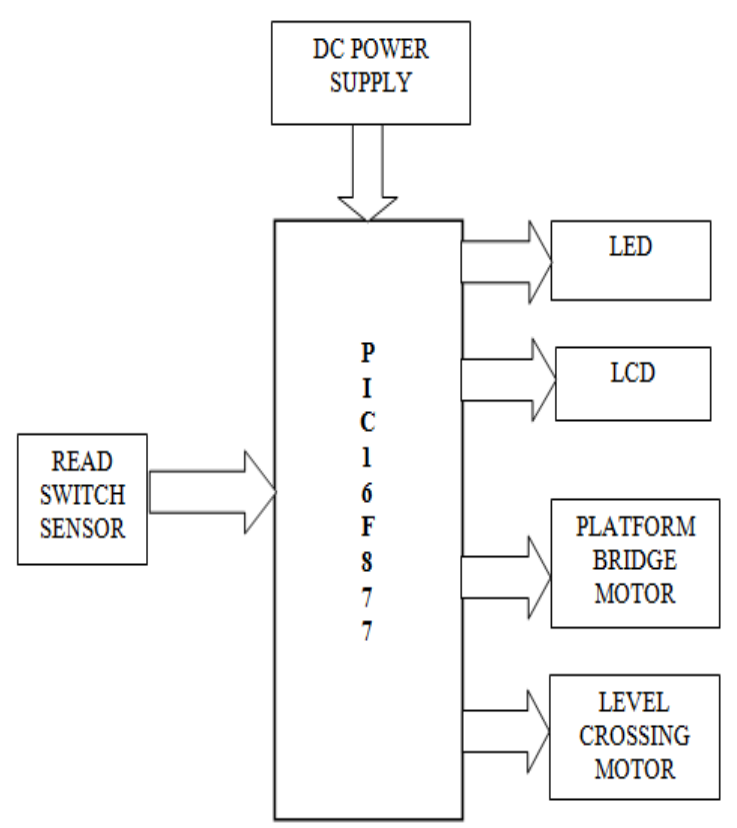

Fig 1: Block diagram of controlling system

The above diagram gives more information about how, when Microcontroller controls the operations of different sub systems used in the Smart Railway Crossing. Here Microcontroller PIC16F877 type play a role in controlling aspects of whole system basically from sensing of arrival train to opening and closing of both railway gate and plat form bride, in this work focus should be taken to implement new additional feature which will finally makes feel free from accidents, waiting time and ease of crossings the platform with highly sensitive controlling systems.

Previous work has done by most of the authors could only concentrate in avoiding of human lives from death by posing unmanned railway gate opening and closing, of course it's necessary, thus in this paper along with established concepts in level crossing, work has moved in well direction to take measure in crossing of people from plat form to plat form when train departure the station.

\section{WORKING PRINCIPLE OF UNMANNED LEVEL CROSSING}

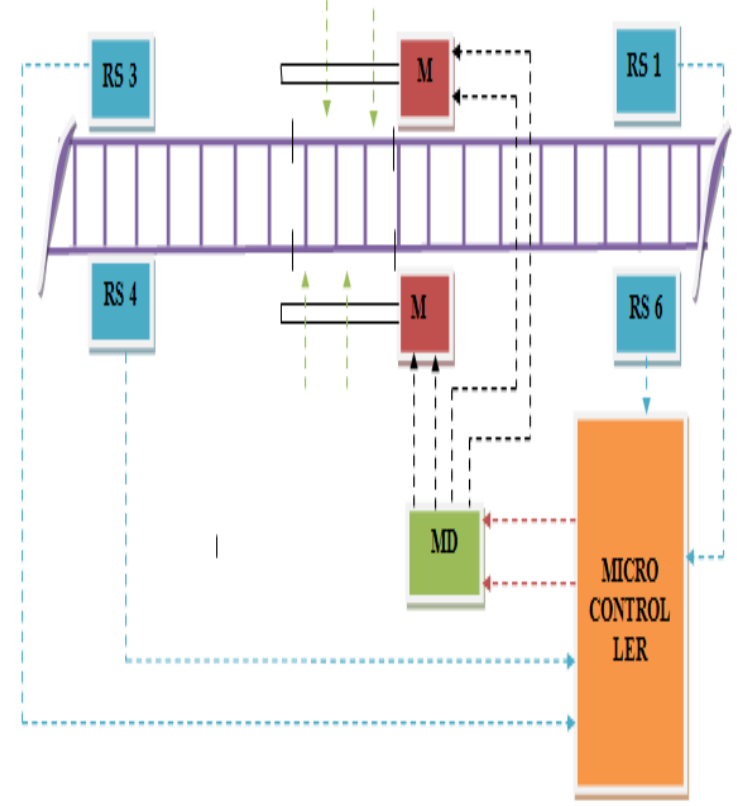

Fig 2: Block diagram of Unmanned Level Crossing

Unmanned Level Crossing system comprises mainly four read switch sensors, these are located at predefined distances and selection parameters to place these sensors based on statistical data collected from survey near places. When train passed across the read switch sensor A1 which senses the movement and send signal to microcontroller, here it will passes a signal to motor driver but this is not instant, once the microcontroller sends the signal before closing of gate first it will give siren for $3 \mathrm{~min}$ time for alerting the pedestrian and vehicle users to take attention. Once the siren stop, the gate automatically close with the aid of motor and when train come across read switch A3, it will send signal to microcontroller and microcontroller drives the motor by sending signal and opening of gate take place this is all going to happen when train moves from right side to left side. The same controlling process will repeat by microcontroller when train travelling from left to right. By this reduce the unexpected accidents due to carelessness of pedestrians and vehicle users. The complete controlling setup replaces manual operation and finally it enhances 
reliability near level crossing, the previous work on this concept uses an IR sensor but in this work used a Read switch sensors.

\section{WORKING PRINCIPLE OF AUTOMATED PLATFORM BRIDGE}

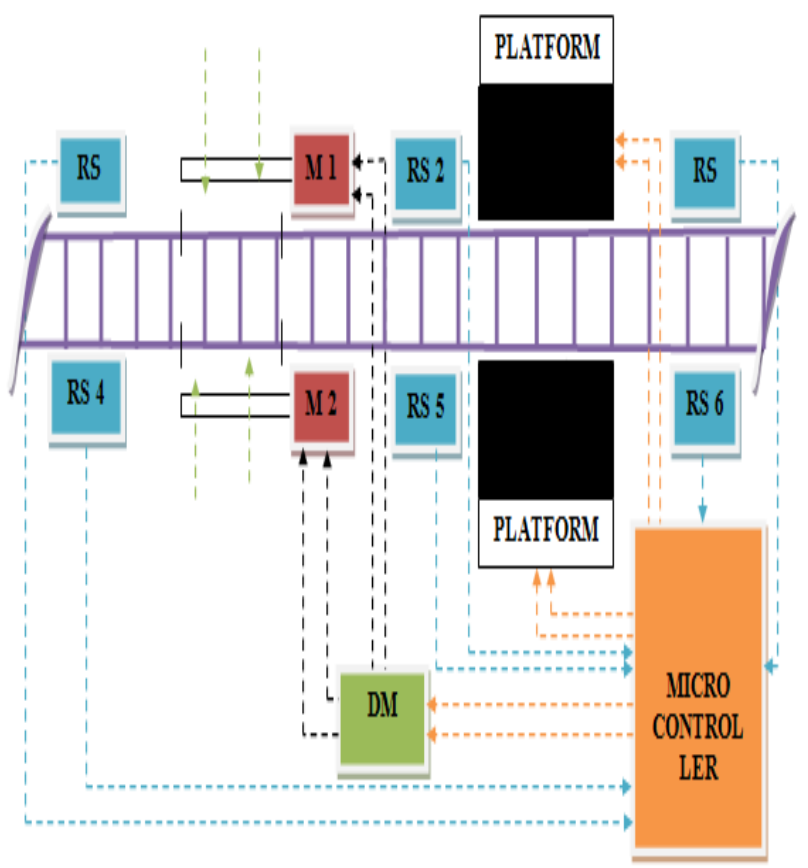

Fig 3: Block diagram of unmanned gate operation and automated platform bridge

RS- Read switch, M- Motor, DM- Driving motor

The fruitful steps often required in the fields, where fatalities are common, example for this one such area are railway transportation system. According to survey the India is most depending nation on railway transportation system, one way of preventing the accidents has taken by adopting unmanned gate operation this will not only save lives and time for which the they wait also diminishes. In other situations the commonly people used flyover to cross railway track but in most of cases people cross the track without aid of flyover along the railway track itself, in other hand aged and patients suffering from many dieses are not having enough strength to cross the track by use of flyover, in account of this measures should be taken in well manner to help them by adopting automated plat form bridge. This will definitely help as they wish and also avoid fatalities in other way by preventing the peoples to cross the track along the track itself.

System comprises mainly microcontroller, two read switch sensor, driving unit, LED display unit and rack and pinion mechanism (present discussion regards to only working of automated platform bridge). When train pass through read switch sensor 1, the signal goes to microcontroller and Rack and pinion mechanism

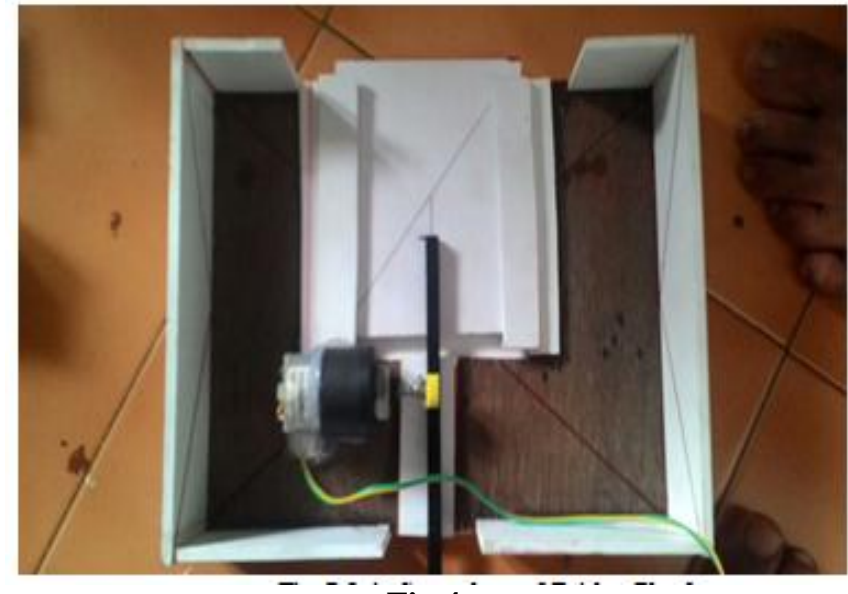

Fig 4

\section{ADVANTAGES}

a) Reduce the chances of human error.

b) Over all time reduces.

c) Fatalities are less.

d) Enhance reliability near level crossing.

e) Enhance reliability at plat form crossing.

\section{CONCLUSION}

The whole work took place in this paper heading towards trying to avoid accidents and reduce the number of fatalities in the field of railway transportation system. Thus basically paper concept through a stone to avoid a two barriers, those of firstly,

Replacing manned type by adopting unmanned type i.e. fully automatic microcontroller based system, this helps in preventing the death caused near level crossing, also decline the time for which the people wait near the level crossing and completely prevent error that has done by gate keeper. Secondly,

To help people those who are physically ill and aged because they are not having enough stamina to climb and Cross the track with the aid of flyover, to keep in mind that use of automated plat form bridge is predominant and did the same in this work. This is the step towards help them and also effective method for those who don't use flyover and cross the track along track itself. 


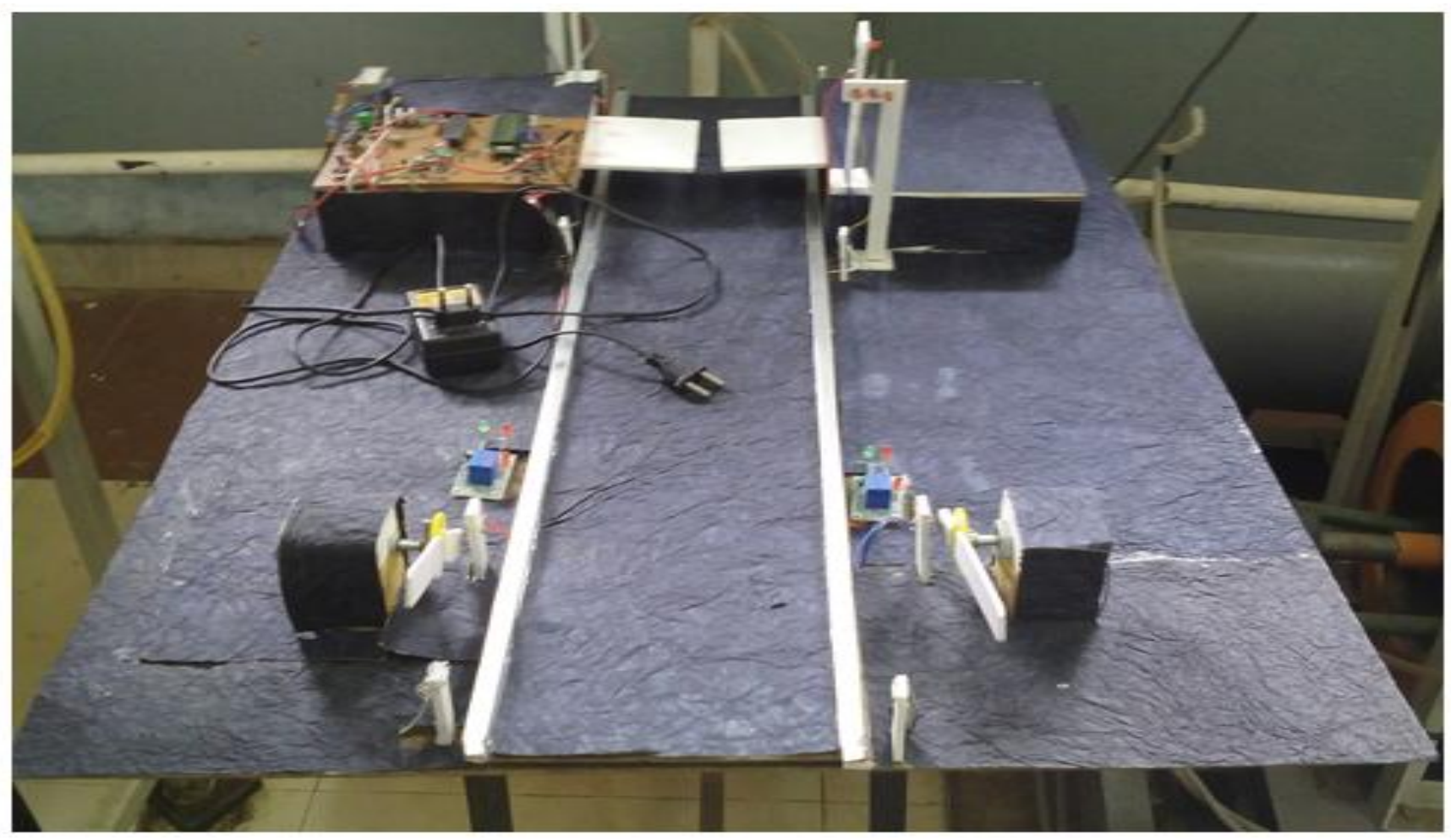

\section{ACKNOWLEDGEMENTS}

We would like to offer our special thanks to college departmental staff's and especially our friends, family member's for giving restless effort in preparation of this paper.

We also convey our sincere gratitude to many of the authors and publications who are providing material as a reference in preparation of this paper.

\section{REFERENCES}

[1] Acy M. Kottalil, Abhijith S, Ajmal M, Abhilash L J, Ajith Babu: "Automatic Railway Gate Control System", Vol.3, February 2014.

[2] Hnin Ngwe Yee Pwint, Zaw Myo Tun, Hla Myo Tun: "Automatic Railway Gate Control System Using Microcontroller", Vol.3, May-2014.

[3] J. Banuchandar, V.kaliraj, P.Balasubramanian, N.Thamilarsi, "Automated Unmanned Railway Level Crossing System” Vol.1, Jan-Feb 2012 PP-458-463.

[4] Krishna, Shashi Yadav, and Nidhi: "Automatic Railway Gate Control Using Microcontroller", Vol.6, No.(4), Pgs.435-440.

\section{BIOGRAPHIES}

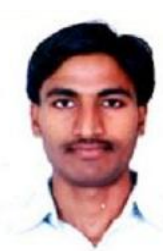

Prashantha.B.Y, BE, MTech in Machine Design, Assistant Professor, Department of Mechanical Engineering, Mukka, Mangalore, Karnataka, India574146.

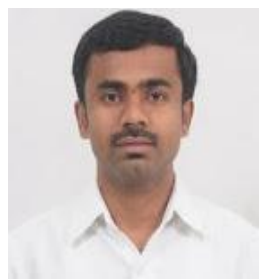

Harisha.S, BE, MTech in Design Engg, Assistant Professor, Department of Mechanical Engineering, DY Patil School of Engineering Academy, Ambi, Pune, Maharastra, India-410506. 